\title{
O Cientificismo como Obstáculo à Compreensão Ético- Política da Psicologia
}

Scientism As An Obstacle For An Ethical-Political Understanding Of Psychology

El Cientificismo Como Obstáculo A La Comprensión Ético Política De La Psicología
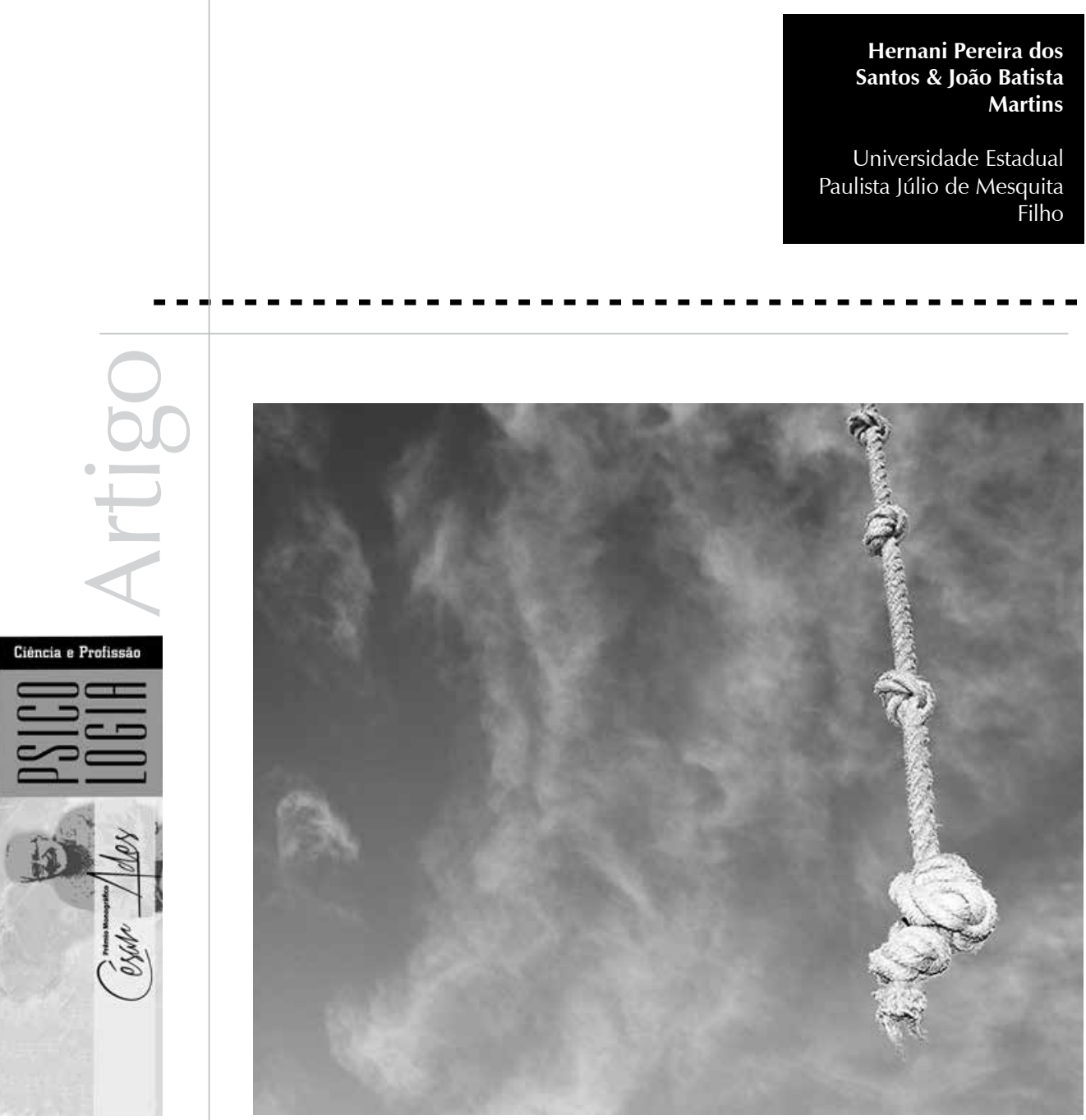
Resumo: Ao dissociarem os fenômenos de seus contextos sociais, humanos e ecológicos e desconsiderarem as categoriais intencionais e valorativas, as metodologias científico-naturais impedem a compreensão de algumas atividades humanas que incluem valores, principalmente os éticos e políticos. Nesse contexto, cientificismo é a aceitação dogmática e não tematizada dos métodos científico-naturais. A partir disso, no contexto da Psicologia, o objetivo deste trabalho é demonstrar de que maneira o cientificismo pode funcionar como obstáculo epistemológico-metodológico a uma compreensão ético-política da Psicologia. Assim, em um primeiro momento, por meio de reflexões baseadas em problemas encontrados na literatura sobre o tema, os dogmas do cientificismo e alguns contrapontos são apresentados; em seguida, algumas de suas consequências são abordadas, tomando-se dois exemplos da literatura corrente - a rotulação e as interpretações raciais, e, por fim, um programa de pesquisa que lida com esses problemas é apresentado como alternativa: a Psicologia crítica.

Palavras-chave: Crítica (Filosofia). Epistemologia. Metodologia. Valores.

Abstract: In separating the phenomena of their social, human, and ecological contexts, and by not taking into account intentional and valorative categories, natural-scientific methodologies impede the comprehension of some human activities which include values, chiefly ethical and political. In this context, "scientism" is the dogmatic and non-thematized acceptance of natural-scientific methods. From this point on, in the context of psychology, the aim of this paper is to demonstrate how "scientism" can function as an epistemological and methodological obstacle to an ethical and political understanding of psychology. Thus, at first, through reflections based on problems encountered in the literature on the subject, scientism's dogmas and some counterpoints are presented; some of its consequences are addressed, by taking up two examples from current literature - the labeling and the racial interpretations, and, finally, a program of research which deals with these problems is presented as an alternative: critical psychology.

Keywords: Criticism (Philosophy). Epistemology. Methodology. Values.

Resumen: Al desasociar los fenómenos de sus contextos sociales, humanos y ecológicos y desconsiderar las categorías intencionales y valorativas, las metodologías científico naturales impiden la comprensión de algunas actividades humanas que incluyen valores, principalmente los éticos y políticos. En ese contexto, cientificismo es la aceptación dogmática y no tematizada de los métodos científico naturales. A partir de eso, en el contexto de la Psicología, el objetivo de este trabajo es demostrar de qué manera el cientificismo puede funcionar como obstáculo epistemológico metodológico a una comprensión ético política de la Psicología. Así, en un primer momento, por medio de reflexiones basadas en problemas encontrados en la literatura sobre el tema, los dogmas del cientificismo y algunos contrapuntos son presentados; enseguida, algunas de sus consecuencias son abordadas, tomándose dos ejemplos de la literatura corriente - la rotulación y las interpretaciones raciales, y, por fin, un programa de investigación que lidia con esos problemas es presentado como alternativa: la Psicología crítica.

Palabras clave: Crítica (Filosofía). Epistemología. Metodología. Valores.

Em um texto introdutório de Brown (2008) que diz respeito à condição histórica da pesquisa em Psicologia no século XXI, os programas de pesquisa apresentados como representantes de nosso século possuem uma forte conexão com o sucesso crescente da metodologia científico-natural, como, por exemplo, na neurociência, nos estudos evolutivos e nos estudos cognitivos baseados em modelos computacionais. Nesses programas, é tomada de antemão a concepção da Psicologia como ciência natural e experimental, que visaria à representação da ordem subjacente dos fenômenos e ao estabelecimento de leis e que, assim, dispensaria qualquer interpretação adicional sobre eles. De acordo com esse modelo, a Física serviria, de modo geral, como critério de comparabilidade para avaliar o desenvolvimento do conhecimento científico em Psicologia e a sua cientificidade.

Entretanto, um dos problemas dessa compreensão é o de que, pela redução dos fenômenos ao domínio abstrativo dos fatos, eles resultam dissociados de seus contextos sociais, humanos e ecológicos, e as categorias intencionais e valorativas são desconsideradas (Lacey, 2009a), ao passo que o controle é altamente valorizado (Lacey, 1984, 2010). De fato, a adoção, pela Psicologia, de um modelo de ciência positivista, ou, em outros 
termos, de "estratégias materialistas" e de "possibilidades descontextualizadas" (Lacey, 2010), gera uma dificuldade tanto para a adoção de estratégias alternativas quanto para a compreensão contextualizada de suas próprias práticas. Neste trabalho, essa aceitação dogmática e não tematizada dos métodos científico-naturais, que provoca o esquecimento das raízes da atividade científica, será denominada cientificismo.

Assim, o objetivo deste trabalho é demonstrar de que maneira o cientificismo pode funcionar como obstáculo epistemológicometodológico a uma compreensão éticopolítica da Psicologia. Isso será levado a cabo por meio da exposição de alguns de seus princípios e da exposição de alguns dos problemas por eles gerados, com referência especial aos contornos da Psicologia, e de reflexões baseadas em problemas encontrados na literatura sobre o tema. $\mathrm{Na}$ primeira seção, busco explorar, em linhas gerais, alguns dogmas do cientificismo e apresentar alguns contrapontos a eles. $\mathrm{Na}$ segunda seção, abordo algumas consequências do cientificismo com respeito à atividade teórica e prática em Psicologia, tomando como exemplo o problema da rotulação e o das interpretações raciais. E, por fim, exibo um programa de pesquisa que se propõe a lidar com os pontos cegos do cientificismo: a Psicologia crítica.

\section{Os dogmas do cientificismo e seus pontos cegos}

Eric Voegelin caracteriza o cientificismo a partir de três dogmas principais, quais sejam:

(...) (1) o argumento de que a ciência matematizada dos fenômenos naturais é um modelo de ciência com o qual todas as ciências devem se conformar; (2) que todos os domínios de ser são acessíveis aos métodos das ciências de fenômenos e (3) que toda a realidade que não é acessível às ciências de fenômenos é ou irrelevante ou, em uma forma mais radical do dogma, ilusória. (Voegelin, 1948/2000, p. 170)

A seguir, exploraremos esses três dogmas, identificando a ideia central no tema em questão e oferecendo a cada uma dessas ideias um contraponto.

\section{A Física como modelo}

Atualmente, a noção de paradigma, desenvolvida por Thomas Kuhn em $A$ Estrutura das Revoluções Científicas (1962/2006), desempenha um papel central nas interpretações do progresso científico e das avaliações das credenciais científicas dos programas de pesquisa. Se essa obra de Kuhn buscou compreender e explicar o desenvolvimento científico das ciências naturais por meio de categorias sociológicas e etológicas, a reinterpretação dessas categorias em termos normativos como meio de garantir a legitimidade de algumas ciências, especialmente as humanas, dentre as quais a Psicologia, parece ter ido além da intentio operis de Kuhn (Carone, 1998), colocando, em seu lugar, mais o uso do texto do que sua interpretação. De fato, o conceito de paradigma sofreu uma inflação hermenêutica, obscurecendo as fronteiras entre uma epistemologia descritiva e uma normativa e entre o que é e o que deve ser com respeito ao desenvolvimento científico. Nesse sentido, por exemplo, na década de 60 , cientistas cognitivistas declararam uma revolução no domínio da Psicologia: o sucesso do novo paradigma cognitivista estaria justificado por possuir características de um paradigma de estilo kuhniano (Sturm \& Mülberger, 2012).

A noção de paradigma passou, então, a servir como parâmetro normativo para o julgamento de programas de pesquisa em Psicologia, pressupondo algo como um télos interno ao desenvolvimento dessa ciência (Carone, 1998), cujo polo-ideal seria 
No entanto, deve-se dizer que a atividade científica não inclui, como seu pressuposto necessário, visões de mundo (Lacey, 2009b), como aquelas relacionadas a tal forma de unificação, e que a unidade não é um valor central da atividade científica, mas é secundário, como o valor de beleza matemática (Lacey, 2009a). o estado atual da Física e a sua condição mais ou menos unitária de ciência normal. De maneira geral, podemos dizer que essa noção esteve também associada, de certa forma, aos discursos de crise de unidade na Psicologia (Sturm \& Mülberger, 2012). Nessa direção, parece ter implicado, ao menos, duas formas de conceber a unidade da Psicologia: i) a unidade interna - o paradigma representaria o estatuto unitário da Psicologia, o seu sucesso como ciência normal, que, em período anterior, estaria dividida em escolas conflitantes, não sendo, nesse último caso, mais do que uma ciência pré-paradigmática, e ii) a unidade externa dado que, sendo paradigmática, a Psicologia alcançaria um estatuto semelhante ao da Física atual, poder-se-ia, em certas condições, inferir a unidade da Psicologia no sistema de ciências, tal como almejada pelos positivistas do início do século XX (Strawinski, 1995).

Em alguns casos, podemos dizer que essa busca por unidade - interna e externa - está associada a, pelo menos, um dos tipos de redução apontados por Olimpia Lombardi (1999): a) a redução semântica - a linguagem de um dado domínio objetivo é reduzida à linguagem de outro domínio (por exemplo, o quantificacionismo), b) a redução ontológica - os aspectos dos fenômenos considerados por um domínio objetivo são reduzidos aos aspectos dos fenômenos de outro domínio objetivo (por exemplo, o fisicalismo) e c) a redução metodológica - os aspectos dos fenômenos considerados por um domínio objetivo são investigados por meio dos procedimentos de outro domínio objetivo (esse é o aspecto mais forte do cientificismo).

Um exemplo de reducionismo próprio de nossa época é a aplicação do programa de Ilya Prigogine (1983 citado por Lombardi, 1999) ao estudo dos fenômenos sociais. Esse programa, conhecido como a nova aliança ou a nova ciência do devir, busca introduzir o indeterminismo e a irreversibilidade no conceito de natureza, não só no domínio da Física mas também no domínio dos fenômenos sociais. Segundo ele, ainda, o estudo dos fenômenos sociais só pode ser realizado por meio da aplicação dos procedimentos utilizados em seu programa de ciência física. Em suma, o seu programa também é reducionista (Lombardi, 1999).

Entretanto, colocar a Física como modelo (ou seja, como polo-ideal) do desenvolvimento da Psicologia possui alguns problemas relevantes. No seio dessa tese, há o pressuposto oculto que parece não estar justificado, a saber, o de que haveria um lapso temporal entre as ciências paradigmáticas - especialmente a Física - e as ciências pré-paradigmáticas - as ciências humanas e sociais, das quais faz parte a Psicologia. Em outras palavras, haveria um polo-ideal que representaria o atual e avançado e que supostamente orientaria o desenvolvimento de todas as ciências particulares, que se unificariam internamente e externamente entre o sistema das ciências. Os métodos das ciências mais avançadas deveriam servir de modelo às demais ciências, por causa de seu sucesso em obter resultados, apesar de os diferentes domínios de objetos não coincidirem entre si, em termos presentacionais. Esse é, certamente, um reducionismo metodológico, associado a um reducionismo ontológico, que funciona como norma para o desenvolvimento de outras ciências. No entanto, deve-se dizer que a atividade científica não inclui, como seu pressuposto necessário, visões de mundo (Lacey, 2009b), como aquelas relacionadas a tal forma de unificação, e que a unidade não é um valor central da atividade científica, mas é secundário, como o valor de beleza matemática (Lacey, 2009a). Portanto, a unificação, no sentido aqui aludido (que implica reducionismo), não parece ser meta de todo legítima. O problema da unidade da ciência deve ser discutido para além da concepção reducionista. 


\section{A expansão irrestrita dos métodos científico-naturais}

Poder-se-ia argumentar que a adoção do método científico-natural em Psicologia seja produtiva, visto que a sua expansão, a princípio ilimitada, a domínios de fenômenos cada vez mais amplos é um fato inegável. Apesar de ser essa uma possibilidade real, contudo, dela também deriva um problema concreto, a saber, a desconsideração de domínios da experiência humana que são também relevantes. Como uma questão de princípio, a adoção irrestrita e exclusiva do próprio método científico-natural levaria a essa desconsideração.

É no contexto dessa crítica que podemos entender as alegações de Hugh Lacey (2009a) com relação ao que denominamos cientificismo, e que Lacey (2009a) chama de "metodologias descontextualizadas". O cientificismo envolveria, então, a desconsideração de "categorias do mundo dos valores e da experiência humana" (Lacey, 2009a, pp. 687-688), em proveito do estudo exclusivo de um domínio de fenômenos relativo à natureza, como tem sido concebida na ciência moderna, que só pode ser acessado, porém, por uma metodologia própria, as metodologias descontextualizadas. Como resultado, adotar estratégias científicas alternativas, como aquelas orientadas para valores, seria uma ação pouco motivada pela comunidade científica, inclusive em termos de recursos, e até mesmo rotulada de ideologia - eis o terceiro dogma. Em suma, o cientificismo impediria a aquisição de domínios especificamente humanos.

Além disso, na medida em que as categorias intencionais são a base da atividade científica, ficaria muito difícil compreender a própria ciência sem o uso de uma metodologia e de categorias adequadas. No caso, o que chamamos de cientificismo se associa ao que Lacey (2009a) chama de "metodologias descontextualizadas", ao passo que uma metodologia contextualizada seria necessária para uma compreensão científica dos valores.

\section{As metodologias descontextualizadas e os valores}

A crítica às metodologias descontextualizadas e às estratégias materialistas parte de uma contraposição ao ideal de que a ciência seja livre de valores (Lacey, 1998, 2006, 2010). Tradicionalmente, o objetivo da ciência moderna foi concebido no sentido da representação da ordem subjacente aos fenômenos, isto é, "das estruturas subjacentes, dos processos e interações de seus componentes e das leis, tipicamente exprimidas em termos matemáticos, que os governam" (Lacey, 2009a, p. 682). Assim, supostamente, o mundo seria representado tal como ele é em si mesmo, de modo que os poderes gerativos de estruturas, processos, interações e leis seriam condição suficiente para a explicação dos fatos (Lacey, 2006). Além disso, quando a ciência procede dessa maneira, por uma questão de redução, os fenômenos são descontextualizados:

(...) eles estão dissociados de quaisquer relações que possam ter com os arranjos sociais, com as vidas e a experiência humana, dissociados de qualquer laço com a ação humana, com as qualidades sensíveis e os valores, e dissociados de quaisquer possibilidades que eles poderiam obter em virtude de sua inserção em contextos particulares sociais, humanos e ecológicos. (Lacey, 2009a, p. 683)

A redução da representatividade da ciência aos fatos significa que a formulação de teorias científicas deve obedecer a categorias disponíveis no interior de "estratégias materialistas" (Lacey, 2006, p. 253), quer dizer, as que privilegiam a representação da ordem subjacente aos fenômenos. Dessa maneira, os juízos de valor e qualquer outra 
participação de valores na atividade científica estariam fora do escopo da ciência, visto que ela seria objetiva, restrita a fatos. Do ponto de vista epistemológico, de modo semelhante, esse ideal de ciência distingue fato de valor, e, assim, os enunciados científicos, que são sempre apenas fatuais, não possuem ligações dedutivas com os valores.

Mas a dicotomia entre fato e valor é problemática. Eis algumas das razões que podem ser enumeradas: primeiro, porque a confirmação de fatos é parcialmente constituída por juízos cognitivos (por exemplo, adequação empírica, poder explicativo e consistência), que possuem, basicamente, as mesmas características formais de juízos éticos e sociais; segundo, porque há pressuposições de juízos de valor em enunciados fatuais, isto é, implicaturas (Lacey, 2006, p. 257); terceiro, porque algumas sentenças não são neutras em suas implicações lógicas, podendo ser usadas em função de enunciados fatuais e, ao mesmo tempo, de juízos de valor; quarto, porque a avaliação de teorias e hipóteses no contexto de aplicação requer juízos de valor acerca de sua legitimidade ética, o que torna importantes as discussões sobre os riscos dessas aplicações e sobre possíveis alternativas (Lacey, 2008); quinto, porque a valorização moderna do controle, advinda da ciência, "contribui para formar a estrutura e os interesses primários das instituições científicas" (Lacey, 2006, p. 262) e, inclusive, para favorecer a escolha de determinadas teorias (Lacey, 1984).

Com base nisso, podemos avaliar alguns dos ideais desse modelo tradicional de ciência. Frequentemente, no lugar de ocorrer uma avaliação a partir de uma multiplicidade de perspectivas de valor, as teorias corretamente aceitas da ciência moderna tendem a favorecer perspectivas de valor que contemplem a valorização moderna do controle. Por esse motivo, o seu ideal de neutralidade - de que a ciência não possuiria nenhum compromisso com quaisquer valores particulares - se torna problemático. Do mesmo modo, se há uma participação de juízos éticos e sociais relevantes no contexto de aplicação da ciência, também o seu ideal de autonomia se torna questionável. Entretanto, considerando que não há, efetivamente, uma sobreposição entre os valores éticos e os valores cognitivos (aqueles componentes da avaliação do conhecimento científico), o que é possível de ser constatado a partir de uma investigação sobre os valores científicos (Lacey, 2010), o ideal da imparcialidade - a saber, o de que as decisões sobre teorias não implicam tal sobreposição - ainda permanece defensável. Por causa disso, a atividade científica permanece compreensível e legítima.

Ao mesmo tempo, uma defesa do pluralismo metodológico é necessária para garantir que outras estratégias ou perspectivas também sejam valorizadas (Lacey, 2009a). Com isso, estratégias com base em categorias intencionais e valorativas se tornam possíveis e, com elas, metodologias adequadas ao estudo de determinados aspectos da conduta humana, em especial os valorativos e intencionais (Lacey, 2009a). Ainda, tornam-se importantes investigações empíricas - aqui, para além do sentido de experimental - sobre riscos e danos da atividade científica moderna e, também, de alternativas potenciais (Lacey, 2008, 2009a), em suma, investigações que levem em conta não apenas a eficácia da aplicação mas também a sua legitimidade (Lacey, 2008). Entretanto, para a efetivação dessas propostas, seria necessária uma "reinstitucionalização da ciência", a qual forneceria, então, os meios para o pluralismo metodológico (Lacey, 2009a). 
1. Compare-se com os comentários de Nalli: “(...) se o médico entra no internamento, não é com o intuito de atuar sobre o interno como doente, mas sim, para proteger os cidadãos daqueles internos que são evidentemente incuráveis. Fol sob o signo do incurável atribuído a uma parcela característica dos desarrazoados, os loucos, que se exigiu a presença constante do médico, não para efetuar uma taxinomia da loucura entre as múltiplas doenças, como outrora, mas sim, por um lado, para nomear 'incurável' esse ou aquele detento, distinguindo-o assim dos demais, e, por outro, defender de todos esses detentos todos os cidadãos livres (...)" (Nalli, 2006, p. 89).
As investigações sobre os pontos cegos do cientificismo devem, pois, partir dessas considerações. Na Psicologia, podemos observar algumas consequências desses pontos cegos do cientificismo, como no fenômeno da rotulação e no das interpretações raciais, o que será visto na seção seguinte. Desde já, a sua análise é um rompimento com o cientificismo: de fato, o método deve ser adequado a seu objeto, a seu movimento imanente, e não o contrário.

\section{Pontos cegos do cientificismo na prática psicológica e o esboço de uma alternativa}

Aqui não tratarei de questões sobre a influência externa de interesses no uso do conhecimento psicológico. A ênfase está em algumas consequências sociais que decorrem de pontos cegos da própria metodologia científica utilizada pela tendência da Psicologia que até aqui associamos ao cientificismo. Para ilustrar esse ponto, cujos princípios foram debatidos na seção anterior, seleciono dois exemplos da prática psicológica: a questão da rotulação e a questão do racismo nas interpretações de dados empíricos. Esses pontos serão entrelaçados por meio de uma compreensão pragmática da linguagem, segundo a qual é central a interrogação sobre o discurso e os seus efeitos éticos e políticos. Por fim, buscarei apresentar um programa de pesquisa em Psicologia que se propõe a lidar com esses problemas: a Psicologia crítica.

\section{Rótulos e ação sob uma descrição: consequências do discurso científico}

Para o pensador francês Michel Foucault (nascido em 1926, falecido em 1984), a efetividade do discurso é uma questão central. Diante do problema colocado pela cisão entre o louco e o homem sensato, a partir de História da Loucura (1961/1978), Foucault mostra que as efetuações de sentido do "sujeito do conhecimento" - no caso, a cisão e a descrição operadas pelo especialista - implicam concreções histórico-sociais. É, portanto, impossível separar a descrição do fenômeno loucura de seu contexto valorativo de origem. Além disso, Foucault nos mostra a maneira como as comunidades históricas abrangidas pelo escopo de seu estudo agiram com relação àquelas pessoas que receberam o rótulo outorgado pelos especialistas, com alto grau de valor agregado, a depender do contexto, de louco - em geral, destinandoos ao confinamento, à exclusão, com o fim imediato de controle ${ }^{1}$. Certamente, isso não quer dizer que não haja alternativas. É essa, na verdade, a busca dos movimentos da reforma psiquiátrica e da luta antimanicomial (Amarante, 2007).

De modo semelhante, o estudo de lan Hacking (1995) sobre o transtorno de múltipla personalidade, Rewriting the Soul, investiga as relações entre os discursos sobre o transtorno em questão, as ciências da memória, por um lado, e as vivências das pessoas rotuladas pelo signo do transtorno, algo que o próprio autor chama de "ação sob uma descrição" (1995, p. 235), por outro. Segundo o autor, o conhecimento sobre a memória contribuiu, em certo sentido, para a secularização da alma, de tal forma que uma série de ações comumente interpretadas em termos de "defeitos da alma" (1995, p. 5), como o abuso das crianças pelos pais, passaram a ser interpretadas em termos de conhecimento científico.

Ainda uma consequência desse discurso científico da memória é o papel que desempenham as descrições no que o autor chama de "ação sob uma descrição" (Hacking, 1995). Para ele, as ações intencionais são 
2. Há vários estudos que sugerem, em direção semelhante, efeitos

iatrogênicos do discurso científico sobre os relatos de memória, principalmente os que incluem o abuso infantil. Ver uma série de resenhas publicadas em Archives of Sexual Behavior, v. 29, n. 5, 2000.

3. Não obstante, podemos considerar o fenômeno consequência de um problema metodológico, embora em sentido mais

amplo, dado que as metodologias tradicionais não permitiram o uso de estratégias alternativas, tampouco permitiram a consideração

de riscos do uso das estratégias tradicionais. ações desempenhadas "sob uma descrição", isto é, as descrições de comportamentos também servem para guiá-los. Nesse sentido, o autor afirma que as descrições de pessoas ou de comportamentos realizadas pela ciência os rótulos - afetam as vivências das pessoas, a maneira como elas narram e interpretam as suas próprias vidas e explicam as suas próprias ações; além disso, contribuem até mesmo para a criação de novas formas de vida. E talvez o problema mais grave do ponto de vista ético para essa questão seja a possibilidade de a terapia gerar falsas memórias sobre um pretenso abuso infantil que jamais existiu (Hacking, 1995) ${ }^{2}$.

Certamente, o fenômeno aqui selecionado, a rotulação, poderia ser estendido a uma multiplicidade de práticas científicas atuais, tanto nos domínios da Psicologia quanto nos da psiquiatria. De qualquer forma, esses são dois estudos exemplares de uma perspectiva que endossa, em certo sentido, as metodologias contextualizadas e que lança luz sobre os pontos cegos do cientificismo. De um lado, mostra-se que a questão genética sobre a descrição de pessoas ou comportamentos não pode dispensar o estudo das estruturas históricas e sociais e ater-se apenas à descrição do fenômeno; de outro, que essas descrições possuem consequências importantes para a vivência humana. Estudar tal fenômeno na concretude da prática do psicólogo exige, assim, a adoção de uma metodologia adequada, que abarque e torne possível o acesso ao domínio próprio da prática humana, social-histórica e intencional, e às consequências sociais de tal prática. Ao mesmo tempo, exige o abandono da atitude natural na qual a descrição é tomada como neutra e autônoma.

\section{Interpretação e racismo: a violência epistemológica}

As interpretações são, para Thomas Teo (2011), um componente essencial da atividade científica em Psicologia, que inclusive predominam sobre os experimentos. Por mais que isso seja verdadeiro, entretanto, verifica-se, na história da Psicologia, uma repressão da hermenêutica em detrimento da metodologia científico-natural tradicional, garantida em grande parte pelo sucesso associado ao cientificismo, o que acontece, por exemplo, na Psicologia racial. Com isso, as diferenças investigadas nos estudos da Psicologia racial sobre grupos étnicos passaram a ser naturalizadas, e as suas evidências passaram, cada vez mais, a basear-se em um "enquadramento de hereditariedade" (2011, p. 241), quer dizer, em um plano metodológico segundo o qual, a partir dos resultados empíricos que mostram as diferenças, assume-se previamente que elas sejam parcialmente herdadas.

Entretanto, na concepção de Teo, os adeptos da Psicologia racial não se deram conta de que os resultados por eles referidos acomodam, a princípio, uma multiplicidade de interpretações. Ao mesmo tempo, ignoraram que interpretações ligadas a conotações de inferioridade ou que têm consequências negativas para grupos étnicos constituem decisões. Evidentemente, não há qualquer princípio metodológico, fornecido pela estratégia seguida, que oriente o pesquisador a interpretar proposições experimentais de maneira específica; em contrapartida, as próprias proposições teóricas permitem vários modelos experimentais. Dessa forma, para o autor, as interpretações ligadas a ideias de inferioridade ou que trazem consequências negativas para certos grupos étnicos se devem a um "déficit hermenêutico dos pesquisadores" (2011, p. 246), mais do que a um problema metodológico ${ }^{3}$. Esse 
4. De modo semelhante, Teo (2010) defende um pluralismo metodológico adequado aos variados níveis ontológicos dos objetos de estudo da Psicologia: do natural ao histórico-cultural. Aliás, sugere, também, que o referencial teórico se relacione à maneira de um rizoma (Teo, 1999). déficit pode ser observado em situações nas quais não há a compreensão das dimensões epistemológicas, ontológicas e éticas no estudo das diferenças e nas quais, ao mesmo tempo, a disciplina não fornece regras, critérios e orientações para interpretações válidas. Além do déficit hermenêutico, não obstante, ocorre também um tipo de inflação hermenêutica, na qual uma interpretação, entre muitas possíveis, é apresentada, por meio das credenciais científicas de que goza socialmente, como conhecimento, e é assim publicada em periódicos científicos.

Considerando que as interpretações publicadas são formas de ação, e que produzem efeitos sobre e nas práticas sociais, podemos dizer que as suas consequências concretas são um ponto de interesse para avaliar riscos inerentes à atividade prática e teórica em Psicologia. Elas podem ser benéficas ao Outro, permanecendo subdeterminadas pelos dados e não acarretando prejuízos. Mas elas podem, também, acarretar consequências prejudiciais ao Outro, em suas possibilidades de ser com os outros. Esse último caso configura o que Teo (2011) chama de "violência epistemológica". As suas consequências são diversas e constituem, também, objeto da Psicologia crítica, da qual falaremos a seguir.

\section{A Psicologia crítica como uma alternativa possível}

Durante o século XX, as psicologias éticopolíticas analisaram criticamente os discursos de seu tempo, mas sem que houvesse qualquer identidade ou qualquer compreensão reflexiva sobre a sua possível condição de uma pesquisa ética geral: nomeavam-se marxistas, feministas, pós-modernistas ou, ainda, pós-colonialistas (Teo, 2005). A busca por consolidar um programa de pesquisa unitário para lidar com essas questões é um assunto relativamente recente.
Tendo Thomas Teo (1998, 1999, 2005, 2010, 2011) como um de seus principais expoentes, dentre outros, esse programa, chamado de Psicologia crítica, envolve a função do conhecimento em Psicologia subscrito pelo termo crítica, por comparação a cultura e a scientia: crítica seria a função de desconstruir, reconstruir e construir o conhecimento psicológico com o fim de mudar as suas práticas (Teo, 1999). Essa crítica deve ser dirigida, pois, à interação dos psicólogos com o mundo, à ciência e à cultura criadas por eles, as quais, em consequência, desempenham funções importantes na ação e na vida cotidiana das pessoas em geral. Ao lidar com problemas como a exploração, a humilhação, a degradação e a injustiça, a Psicologia crítica exige uma "teoria psicológica da libertação" (Teo, 1998, p. 536), que lida diretamente com problemas de poder, opressão e emancipação. Para tanto, inclui, em seu arcabouço teórico, as contribuições do marxismo clássico, do neomarxismo e do pós-marxismo (Teo, 1998, 2011). Ainda um exemplo de metodologia da Psicologia crítica oferecido por Teo $(1998,2011)$ é a questão já comentada do racismo, sobre a qual forneceria uma aplicação diferenciada do termo em contextos comunicativos e com vistas à emancipação dos oprimidos.

Com certeza, poderíamos incluir aí as análises de Lacey das estratégias materialistas e das possibilidades descontextualizadas, a sua defesa de um pluralismo metodológico adequado aos objetos estudados ${ }^{4} \mathrm{e}$ do estudo de aspectos importantes da vida humana, como os valores e as categorias intencionais (Lacey, 2009a), e da atividade científica, como riscos e alternativas (Lacey, 2008).

\section{Considerações finais}

Por mais que os problemas aqui tratados sejam 
problemas de ordem metateórica, as suas consequências sobre a ação dos psicólogos, seja na atitude teórica, seja na atitude ético-política, é de imediata importância, ainda mais se considerarmos que, muitas vezes, a Psicologia foi utilizada como instrumento de poder (Foucault, 1957/1994), em geral a serviço das elites (Bock, 2003), ou, ainda, que as interpretações psicológicas tiveram consequências negativas sobre determinados grupos étnicos (Teo, 2011). Certamente, esses fatos se devem, pelo menos em parte, a problemas internos da metodologia científico-natural e à dispensa de interpretação adicional dos psicólogos sobre os fenômenos por eles estudados ou, ainda, sobre os compromissos, os preconceitos e os lemas ocultos da Psicologia tradicional.

Partimos dessa ideia inicial e, assim, buscamos levar adiante a interpretação da Psicologia para além de seus métodos tradicionais e evidenciar os seus pontos cegos e algumas de suas consequências éticas e políticas. Assim, chegamos a apresentar a Psicologia crítica como um programa de pesquisa que lidaria com esses problemas. A metodologia tradicional, guiada pelos dogmas cientificistas, ocultou-os ou mesmo rejeitou-os como ideologia. Hoje eles compõem um conjunto de problemas com os quais a Psicologia atual deve lidar, principalmente se o que está em jogo é a sua cientificidade e a legitimidade de suas aplicações.

A restrição metodológica da Psicologia, em sua história recente, criou esse impasse. No entanto, o seu sucesso crescente em alcançar resultados escamoteou o problema, o que se traduz na unilateralidade metodológica dos programas atuais em Psicologia. Oporse a essa restrição não significa, pois, uma oposição à própria ideia de ciência como tal, pelo contrário, significa a defesa de uma ciência que se desenvolve em direção à concretização do mundo, e não mais à sua abstração. Isso exige, certamente, uma crítica da visão unilateral - abstrativa - até então predominante. Ao mesmo tempo, trata-se de um direcionamento da atenção a setores da experiência anteriormente negligenciados e cuja negligência não poderia ser nada mais do que prejudicial, como vimos nos exemplos citados neste trabalho.

Além disso, as soluções, atuais e potenciais, aos tipos de problemas aqui sublinhados não são, essencialmente, neutras, visto que possuem consequências sociais de curto e de longo prazo - estão, portanto, estruturalmente ligadas à vida social e aos mais diversos aspectos que compõem a sua totalidade. Por esse motivo, as discussões científicas em Psicologia não podem restringir-se à busca de soluções eficazes, mas devem orientar-se para a busca de soluções legítimas (Lacey, 2008). Defender o pluralismo metodológico significa, nesse sentido, tornar a situação comunicativa aberta a uma pluralidade de estratégias de pesquisa e a discussões de alternativas.

Os problemas que apresentamos não são, certamente, os únicos. A atividade dos psicólogos possui diversas consequências no mundo humano ainda pouco avaliadas, como se poderia sugerir, por exemplo, com respeito às propostas de aplicação da teoria à política, em termos meramente instrumentais, que reproduzem o modelo de ciência tomado de antemão, sem análise. A Psicologia crítica possui um amplo leque de possibilidades investigativas que ainda devem florescer. Este trabalho ilustra apenas uma pequena parte do caminho possível de ser percorrido. 
Hernani Pereira dos Santos

Pós-Graduando do Programa de Mestrado em Psicologia da Universidade Estadual Paulista Júlio de Mesquita Filho - UNESP, Assis - SP - Brasil.

E-mail: hernanips@msn.com

\section{João Batista Martins}

Pós-doutor em Educação pela Universidade de Brasília. Docente do Departamento de Psicologia Social e Institucional da Universidade Estadual de Londrina e da Pós-Graduação em Psicologia da Universidade Estadual Paulista Júlio de Mesquita Filho - UNESP, Assis - SP - Brasil.

E-mail: jbmartin@sercomtel.com.br

\section{Endereço para envio de correspondência:}

Rua da Ermida, 306. CEP 86191-140. Cambé, PR. 


\section{Referências}

de Janeiro: Editora Fiocruz.

Bock, A. M. B. (2003). Psicologia e ideologia: 40 anos de compromisso com as elites. In A. M. B. Bock (Org.), Psicologia e compromisso social (pp. 15-28). São Paulo: Cortez.

Brown, J. C. (2008). Psychology into the 21st century. In W. F. Buskist \& S. F. Davis (Eds.). 21st century psychology: a reference handbook. Thousand Oaks, CA: SAGE Publications.

Carone, I. (1998). A questão dos paradigmas na psicologia: um balanço crítico. Psicologia em Estudo, Maringá, 3(1), 191-200.

Foucault, M. (1994). La recherche scientifique et la psychologie. In M. Foucault. Dits et écrits. (pp. 137-158). Paris: Éditions Gallimard (Trabalho original publicado em 1957).

Foucault, M. (1978). História da loucura na idade clássica (J. Teixeira Coelho Neto, trad.). São Paulo: Editora Perspectiva (Trabalho original publicado em 1961).

Hacking, I. (1995). Rewriting the soul: multiple personalities disorder and the sciences of memory. Princenton, New Jersey: Princenton Universy Press.

Kuhn, T. S. (2006). A estrutura das revoluções científicas (9a ed., B. Vianna Boeira \& N. Boeira, trads.). São Paulo: Perspectiva (Trabalho original publicado em 1962).

Lacey, H. (1984). A posição de Skinner acerca da predição e controle do comportamento. Cadernos de História e Filosofia da Ciência, 6, 5-33.

Lacey, H. (1998). Valores e atividade científica. São Paulo: Discurso Editorial.

Lacey, H. (2006). Relações entre fato e valor. Cadernos de Ciências Humanas - Especiaria, 9(16), 251-266.

Lacey, H. (2008). Ciência, respeito à natureza e bem-estar humano. Scientiae Studia, 6(3), 297-327, doi: http://dx.doi. org/10.1590/S1678-31662008000300002

Lacey, H. (2009a). O lugar da ciência no mundo dos valores e da experiência humana. Scientiae Studia, 7(4), 681-701. doi: http://dx.doi.org/10.1590/S1678-31662009000400010
Lacey, H. (2009b). The interplay of scientific activity, worldviews and value outlooks. Science \& Education, 18, 839-860. doi: 10.1007/978-90-481-2779-5 10

Lacey, H. (2010). Valores e atividade científica 2. São Paulo: Editora 34

Lombardi, O. (1999). Prigogine y la reducción em ciências. Cadernos de História e Filosofia da Ciência, 9(1-2), 123-145.

Nalli, M. A. G. (2006). Foucault e a fenomenologia: leituras filosóficas. São Paulo: Edições Loyola.

Prigogine, I. (1983). ¿Tán Sólo una llusión?. Barcelona: Tusquets.

Strawinski, W. (1995). The unity of science today. Poznan Studies in Philosophy of the Sciences and the Humanities, 44, 295-304.

Sturm, T., \& Mülberger, A. (2012). Crisis discussions in psychology: New historical and philosophical perspectives. Studies in History and Philosophy of Biological and Biomedical Sciences, 43, 425-433. doi: 10.1016/j.shpsc.2011.11.001

Teo, T. (1998). Prolegomenon to a contemporary psychology of liberation. Theory \& Psychology, 8(4), 527-547. doi: 10.1177/0959354398084006

Teo, T. (1999). Functions of knowledge in psychology. New Ideas in Psychology, 17, 1-15.

Teo, T. (2005). The critique of psychology: from Kant to postcolonial theory. New York: Springer.

Teo, T. (2010). Ontology and scientific explanation: Pluralism as an a priori condition of psychology. New Ideas in Psychology, 28, 235-243. doi:10.1016/j.newideapsych.2009.09.017

Teo, T. (2011). Empirical race psychology and the hermeneutics of epistemological violence, Human Studies, 34(3), 237-255. doi: 10.1007/s10746-011-9179-8

Voegelin, E. (2000). The origins of scientism. In E. Sandoz (Ed.). The collected works of Eric Voegelin, (V. 10: published essays -1940-1952, pp. 168-196). London: University of Missouri Press (Trabalho original publicado em 1948) 